\title{
Obituary of Jack K. Hale
}

\author{
Shui-Nee Chow · John Mallet-Paret
}

Received: 17 May 2010 / Published online: 23 June 2010

(C) Springer Science+Business Media, LLC 2010

Jack Kenneth Hale was born in Carbonglow, Kentucky, on October 3, 1928, and died in Atlanta, Georgia, on December 9, 2009. In his life he was a leading international figure in differential equations and dynamical systems, as well as a colleague, mentor, and trusted friend to many scholars in this and other areas of mathematics and science. In this brief sketch we hope to capture some features of his life, both professional and personal.

Jack's family was of modest means (his father managed a mining-company store) in a part of the US which was then quite poor. Jack grew up in Kentucky, with his family moving several times to various locations in that state. He graduated from Martin High School in Martin, Kentucky, in 1944, and proceeded then to undergraduate studies at Berea College, in Berea, Kentucky, from 1944 to 1949.

Berea College was, and is, an exceptional liberal arts college in many ways. Founded in 1855 by abolitionists, it was coeducational and interracial at a time when this was almost unheard of. (Sadly, from 1904 to 1950 it was made all-white by force of the "Day Law," which forbade racially mixed schools.) Many students were from low-income backgrounds, and all students were required to work, often physical labor, at least 10 hours per week at the college as payment toward room and board, and as part of their educational experience. Being tall and lanky made Jack a natural for the Berea basketball team, which led to a lifelong love of the game. Indeed, well into his fifties, Jack would be found besting guys half his age in a pickup game.

Upon graduation from Berea, Jack married Hazel Reynolds, who was his devoted wife and companion until his death. As many know, Hazel often accompanied Jack on his travels and as a result she became a dear friend to many mathematicians throughout the world. At conferences Hazel could be found leading her friends on tours of the local art museums and galleries. She acquired much knowledge of the art of the world, gleaned from extensive travels, and she became particularly fond of the works of young innovative artists, which

\section{S.-N. Chow}

School of Mathematics, Georgia Institute of Technology, Atlanta, GA 30332, USA

J. Mallet-Paret $(\bowtie)$

Division of Applied Mathematics, Brown University, Providence, RI 02912, USA

e-mail: jmp@dam.brown.edu 
she would add to her and Jack's personal collection. In an interview with the authors shortly before his death, Jack stated that "no matter how highly you regard your research, you must not forget the family. One must realize that to be well-recognized in your profession takes time. However, one cannot succeed without the support and involvement of the family. I couldn't have done well without Hazel sacrificing and giving up a lot so that I could pursue my work."

From 1949 to 1953 Jack was a graduate student at Purdue University under the direction of Lamberto Cesari. This was followed by one more year at Purdue as an instructor. Under Cesari's direction, Jack became acquainted with dynamical systems, and specifically, with nonlinear oscillations, which was the topic of his Ph.D. thesis "On the Asymptotic Behavior of the Solutions of Systems of Differential Equations." This was an area in which Cesari, who had previously worked in calculus of variations and surface area, had recently become interested. In fact, at that time, in the West there was very little interest in dynamical systems or generally in the mathematical theory of differential equations, and in this sense Jack was one of the pioneers in opening this area.

After Purdue, Jack worked for the Sandia Corporation in Albuquerque, New Mexico, until 1957, and following that for Remington Rand in St. Paul, Minnesota, for a year. In 1958 he joined the Research Institute for Advanced Studies (RIAS) as a permanent member. RIAS was the research arm of the Glenn Martin Company, and was housed far from the main manufacturing plant in a lovely old mansion belonging to the Hopkins family in a suburb of Baltimore, Maryland. Jack's place in the organization was with a recently-formed group headed by Solomon Lefschetz, which was devoted to the study of nonlinear differential equations and control. Although the group was small, there was an active visitors program with researchers from around the world, and the members of the group had no specific obligation to the Martin Company other than to further research in the area. As Jack stated, "This created an atmosphere in which ideas were exchanged freely. This helped in coordinating and accelerating the research in the subject, not only at RIAS, but at the institutions of the visitors." It was also at RIAS that Jack met Joseph P. (Joe) LaSalle, who would be instrumental with Jack in furthering the development of dynamical systems in America. The emphasis on dynamical systems and control theory was very timely, particularly in the context of aerospace applications. This was a period of intense competition between the US and the Soviet Union in space, including the goal of putting humans on the moon.

With Lefschetz and LaSalle, Jack studied and developed not only fundamental aspects of nonlinear oscillations, but also such basic qualitative ideas as attractors for dissipative systems and invariant manifolds. In one of Jack's earliest papers [4], he examined a class of perturbed linear oscillators and made basic contributions to the areas of nonlinear oscillations, averaging methods, integral manifolds, and almost periodic systems. The perturbations he considered were nonlinear and time-dependent, possibly almost periodic in time, but otherwise quite general. Jack obtained criteria describing which oscillations survived the perturbation, and as well he described their stability. In modern language, he obtained a weakly hyperbolic invariant torus. Older results had required the perturbation to be a polynomial, while here the dynamical approach allowed for a very general type of smooth perturbation.

In 1964 the Martin Company decided that the research of the RIAS groups should be more directly related to the company's manufacturing. As a result, the mathematics group at RIAS sought a more academic atmosphere to continue their research as a group. This was done, with Lefschetz, LaSalle, as well as Jack and other colleagues moving en masse to Brown University. (Although Lefschetz lived in Princeton, he commuted weekly to Brown after the move.) Such a move today would be almost impossible, but in those days it was still possible to "cut a deal" as a group. At Brown, the group was rebranded as the Center for Dynamical Systems 
(and later, after Lefschetz' death, as the Lefschetz Center for Dynamical Systems [LCDS]). For the most part the Center was a subset of the Division of Applied Mathematics (one of the departments at Brown), although there was enough autonomy that the Center achieved a worldwide recognition on its own. Jack was a member of the Center until his departure from Brown in 1988. During that period he nurtured and sustained it as a leading venue for research in differential equations, with top faculty, a robust visitors program, and excellent students. It was at Brown that the Journal of Differential Equations was founded, first with LaSalle as Editor-in-Chief, then followed by Jack after LaSalle's death. Jack remained active in his editorial duties with the Journal until his death, and he was very largely responsible for making it one of the premier outlets for high-quality research in differential equations and dynamical systems.

It is interesting to note the symbiotic roles played by Jack, with LaSalle and Lefschetz, in the development of a major mathematical research center in the US, first at RIAS and later at Brown. Both Jack and Joe LaSalle had been working (separately) in mathematics for some time, when they joined efforts with Lefschetz in 1958. Lefschetz brought a special international connection, being very familiar with the work in the Soviet Union on dynamical systems. He regularly wrote Mathematical Reviews of the Russian literature on dynamical systems during this period. Since Lefschetz was one of the few persons outside the Soviet Union who was familiar with the Soviet work, this facilitated the ability of the research center to build a bridge between the US and Europe, and especially Eastern Europe. This was quite unusual for the time, as scientific contacts between East and West were extremely rare and could only be arranged with great difficulty. This was particularly significant, as the Soviet Union then enjoyed a rich mathematical life in differential equations and dynamical systems, unlike much of the West. Among the visitors from the Soviet Union and Eastern Europe that Lefschetz played a role in bringing to the US were R.V. Gamkrelidze (Georgia), J. Kurzweil (Czechoslovakia), Yu.A. Mitropol'skiü (Ukraine), C. Olech (Poland), V.A. Pliss (Russia), and L.S. Pontryagin (Russia). It can be said that the Hale-LaSalle-Lefschetz trio had a major role in bringing nonlinear differential equations and dynamical systems to prominence outside the Soviet bloc. In this spirit, Jack's paper [4], noted above, not only made fundamental scientific contributions, but was also considered invaluable as an expository work of results which, until then, were only available in the Russian-language literature.

Another example of the Hale-LaSalle-Lefschetz symbiosis was the organization of a very successful international conference in January 1965 in Mayagüez, Puerto Rico. The conference brought together researchers from not only the US, but also from elsewhere in the Americas and many parts of Europe. Many of the younger participants met Lefschetz as well as other international mathematicians for the first time at this conference. For these "youngsters" this conference turned out to be a wonderful introduction to the World of Dynamical Systems, and what these persons experienced in 1965 has turned out to be part of the Jack Hale Legacy.

In the early 1960s Jack developed a very close relation with Brazil, which continued up to his death, and which had a significant impact on the development of the dynamics of differential equations in that country. Beginning with Nelson Onuchic and Mauricio Peixoto at RIAS (and with Peixoto's later position as a professor at Brown), Jack's influence was felt at the University of São Paulo, and contacts with Waldyr Oliva were initiated in the 1960s. In the early 1980s these contacts led, under Jack's influence, to the decision of his former student Daniel Henry to accept a position at The University of São Paulo, with the resulting significant impact for Brazilian mathematics, particularly in São Paulo and São Carlos. During the late 1960s and throughout the 1970s, many Brazilian students and visitors came to Brown, and Jack was the advisor of six of the students. Throughout that period, and later, 
Jack made numerous visits to Brazil, not only to the top institutions, but also to many smaller and less well-known universities.

After the death of Lefschetz in 1972 and the later retirement of LaSalle, Jack was very much the "organizing center" of the Lefschetz Center at Brown throughout most of the 1970s and 1980s. There was a high level of activity maintained there during this period, with numerous visitors, students, and postdocs.

In 1988 Jack left Brown for warmer climes in Atlanta, Georgia, where he, along with one of the authors (Chow), founded the Center for Dynamical Systems and Nonlinear Studies (CDSNS) at the Georgia Institute of Technology. Again, at Georgia Tech, Jack with his colleagues very successfully took on the task of replicating what had been done at Brown, and today Georgia Tech is a top international center for the study of nonlinear dynamical systems. Jack retired from Georgia Tech in 1998, although he remained very active as a mathematician until his final illness.

While at Brown and Georgia Tech, the research of Jack and his collaborators covered a broad and ever-changing landscape, although it was always rooted in the spirit of the qualitative theory of differential equations. Here we can only touch upon a few of Jack's contributions.

The theory of delay differential equations, and more generally functional differential equations, was of great interest to Jack in his early days at Brown. While time-delay systems were always of interest to control theorists and engineers, until then their analysis had been restricted almost entirely to linear systems, and done in a very classical and analytic style. Jack realized early that if progress was to be made in understanding nonlinear functional differential equations, then the geometric approach of qualitative dynamical systems would be needed. At the time, a comprehensive theory of infinite-dimensional dynamical systems was essentially nonexistent, and people thought about dynamics only in terms of finite-dimensional ODE's. Nevertheless, Jack laid out a program to develop the basic tools for studying the nonlinear dynamics of functional differential equations. A seminal paper in this direction was [9], in which a class of integro-differential equations were studied. Such basic notions as variation of constants, sharp exponential bounds, and the method of averaging, were developed in the context of an infinite-dimensional phase space $C\left([-r, 0], R^{n}\right)$. Following a number of other papers in this spirit, the foundational and now classic book [6] was written which set the stage for further studies. The book has undergone several updates, and still today it is one of the basic references in the subject; see [13].

The dynamical approach to infinite-dimensional systems had a great influence on Jack's student Dan Henry. Here the interest was in replicating for nonlinear parabolic PDE's (such as reaction-diffusion systems) what had been done for functional differential equations. Again, at the time, PDE's was very much an analytic subject, and notions of the phase space, invariant manifolds, omega-limit sets, and attractors were not widely considered (not to mention more exotic concepts such as chaotic dynamics). Henry's work in this direction, first with functional differential equations and then with parabolic PDE's, culminated in the classic treatise [15], in which such dynamical concepts were systematically developed for nonlinear parabolic equations. Again, even today, this work remains a basic reference in the subject.

It was recognized early on that the notion of an attractor for an infinite-dimensional nonlinear dissipative system was a fundamental object to be studied. In the mid-1960s and early 1970s much progress was made by Jack and his colleagues in clarifying the basic principles; the papers $[1,5,7,14]$, for example, are representative of these efforts. Later work moved toward understanding the fine structure of attractors for specific classes of equations; for example, questions on the existence of periodic orbits, the presence of bifurcations, and the existence of connecting orbits between invariant sets, were much studied. In [3] the 
evolution of interfaces in a reaction-diffusion equation with small diffusion was studied, with a dynamical description, in terms of invariant manifolds and attractors, and of how such solutions approach equilibria.

A fundamental contribution was made in [11], which described how the global attractor $A_{\varepsilon}$ of an infinite-dimensional dynamical system varies with $\varepsilon$ as $\varepsilon \rightarrow 0$, where the system at $\varepsilon=0$ is gradient-like. An earlier result [10] proved upper semicontinuity of $A_{\varepsilon}$ in the Hausdorff metric in much greater generality. However, obtaining lower semicontinuity is a much more subtle issue than proving upper semicontinuity; indeed, lower semicontinuity does not in general hold due to possible lack of hyperbolicity in the attractor. In [11] sufficient conditions of a dynamical nature were given to ensure lower semicontinuity.

Jack's research took him to many other topics, too numerous to describe in detail here; but to name several, there were problems in neutral functional differential equations and their analysis using Lyapunov-Schmidt methods and degree theory; generic bifurcation theory with an emphasis on multi-parameter problems; and reaction-diffusion problems in thin domains.

Jack's final paper [12], with Geneviève Raugel, was a fundamental contribution that dealt with the persistence of non-degenerate periodic orbits. The class of systems considered contained (among others) damped hyperbolic equations, and the salient feature here was that the dynamical system did not smooth in finite time, but rather was only asymptotically smooth. Jack remained active almost to the end, working with Raugel to finalize this paper, which was completed only a week before Jack's death.

Throughout his career, Jack received wide recognition for his many accomplishments. In 1965 he was awarded the Chauvenet Prize (jointly with LaSalle) for their expository article [8] on nonlinearities in differential equations. Jack was the recipient of a Guggenheim Fellowship in 1979, a British Carnegie Fellowship in 1986, and he received the Sigma Xi sustained research award in 1991. He received honorary degrees from Ghent University (Belgium) in 1982; from the University of Stuttgart (Germany) in 1988; from the Technical University of Lisbon (Portugal) in 1991; from the University of Rostock (Germany) in 1999; and from Clark University (Worcester, Massachusetts) in 2000. (Interestingly, Lefschetz received his $\mathrm{Ph} . \mathrm{D}$. degree from Clark in 1911.) Jack was also a Corresponding Member of the Brazilian Academy of Science, an Honorary Fellow of Royal Society of Edinburgh, and a Foreign Member of the Polish Academy of Science.

One of Jack's most rewarding accomplishments was working with his $47 \mathrm{Ph}$.D. students and numerous postdoctoral fellows; indeed, it was not unusual for Jack to be simultaneously supervising four or five students plus a postdoc or two. Many of these, along with their descendants, have maintained Jack's legacy in various ways, by making significant contributions to dynamics and differential equations, and by educating new generations of scholars and researchers. It is perhaps the case that Berea College, with its ethos of personal initiative and responsibility, coupled with a dedication to equality of opportunity, was a significant influence on Jack's later views toward research, collaboration, and in particular his relation with young people whom he mentored. Many have noted that Jack had a special dedication to young mathematicians, which he bore without prejudice toward their academic background, but which he rather based on their innate talents. Despite his stature, Jack remained extremely approachable, and he was always eager to discuss not only mathematics, but current events, philosophy, sports, and many other topics. (Many such discussions took place at parties and dinners at Jack and Hazel's home, to which students were always welcome.) Jack always encouraged young researchers to follow their interests rather than to succumb to popular and transient mathematical fashion. In this spirit Jack described his research philosophy as "choos[ing] only those topics that are of great interest to you and for which you feel that there 
is further need for long range research, and ones that are compatible with your background. It may be that others may not feel that it is worth the effort. However, if it bothers you, then pursue it until you are satisfied. This requires patience with the expectation that others may never appreciate what you have done. You must work on the things that you enjoy." It has certainly been these authors' experiences, first as postdocs under Jack, and then as his colleagues, that these words ring true, and we believe they serve as excellent advice to any young researcher.

The mathematical world, and certainly the world of differential equations and dynamical systems, has lost an important and influential figure with Jack Hale's passing. But his legacy lives on in his scientific contributions, in the many people he mentored, and in the memory of all those who were touched by his gentle influence, kindness, and friendship.

Acknowledgements The authors are grateful to many people for their helpful suggestions in the preparation of this article. In particular, we thank Constantine Dafermos, Wendell Fleming, Harold Kushner, Kenneth Meyer, Czesław Olech, Waldyr Oliva, Geneviève Raugel, Carlos Rocha, and George Sell. We also acknowledge the articles of Nathaniel Chafee [2] and Yingfei Yi [16], which provided invaluable information. Finally, any errors herein are solely the responsibility of the authors.

\section{References}

1. Billotti, J.E., LaSalle, J.P.: Dissipative periodic processes. Bull. Am. Math. Soc. 77, 1082-1088 (1971)

2. Chafee, N.: Jack K. Hale: A brief biography. J. Differ. Equ. 168, 3-9 (2000)

3. Fusco, G., Hale, J.K.: Slow-motion manifolds, dormant instability, and singular perturbations. J. Dyn. Differ. Equ. 1, 75-94 (1989)

4. Hale, J.K.: Integral manifolds of perturbed differential systems. Ann. Math. 73, 496-531 (1961)

5. Hale, J.K.: Dynamical systems and stability. J. Math. Anal. Appl. 26, 39-59 (1969)

6. Hale, J.K.: Functional Differential Equations. Applied Mathematical Sciences, vol. 3, 238 pp. Springer, New York (1971)

7. Hale, J.K., Infante, E.F.: Extended dynamical systems and stability theory. Proc. Natl. Acad. Sci. U.S.A. 58, 405-409 (1967)

8. Hale, J.K., LaSalle, J.P.: Differential equations: linearity vs. nonlinearity. SIAM Rev. 5, 249-272 (1963)

9. Hale, J.K., Meyer, K.R.: A class of functional equations of neutral type. Mem. Am. Math. Soc. 76, $65 \mathrm{pp}(1967)$

10. Hale, J.K., Lin, X.-B., Raugel, G.: Upper semicontinuity of attractors for approximations of semigroups and partial differential equations. Math. Comp. 50, 89-123 (1988)

11. Hale, J.K., Raugel, G.: Lower semicontinuity of attractors of gradient systems and applications. Ann. Mat. Pura Appl. 154, 281-326 (1989)

12. Hale, J.K., Raugel, G.: A modified Poincaré method for the persistence of periodic orbits and applications. J. Dyn. Differ. Equ. 22, 3-68 (2010)

13. Hale, J.K., Verduyn Lunel, S.M.: Introduction to Functional-Differential Equations. Applied Mathematical Sciences, vol. 99, 447 pp. Springer, New York (1993)

14. Hale, J.K., LaSalle, J.P., Slemrod, M.: Theory of a general class of dissipative processes. J. Math. Anal. Appl. 39, 177-191 (1972)

15. Henry, D.: Geometric Theory of Semilinear Parabolic Equations. Lecture Notes in Mathematics, vol. 840, 348 pp. Springer, New York (1981)

16. Yi, Y.: An interview with Jack K. Hale. Dynamical Systems Magazine. http://www.dynamicalsystems. org. Issue of January 2004 